\title{
The PRECEDE-PROCEED model: application to planning a child pedestrian injury prevention program
}

\author{
Peter Howat, Steve Jones, Marg Hall, Donna Cross, Mark Stevenson
}

\begin{abstract}
Objectives-The objectives were first, to modify the PRECEDE-PROCEED model and to use it is as a basis for planning a three year intervention trial that aims to reduce injury to child pedestrians. A second objective was to assess the suitability of this process for planning such a relatively complex program.
\end{abstract}

Setting-The project was carried out in 47 primary schools in three local government areas, in the Perth metropolitan area.

Methods-The program was developed, based on extensive needs assessment incorporating formative evaluations. Epidemiological, psychosocial, environmental, educational, and demographic information was gathered, organised, and prioritised. The PRECEDE-PROCEED model was used to identify the relevant behavioural and environmental risk factors associated with child pedestrian injuries in the target areas. Modifiable causes of those behavioural and environmental factors were delineated. A description of how the model facilitated the development of program objectives and subobjectives which were linked to strategy objectives, and strategies is provided.

Results-The process used to plan the child pedestrian injury prevention program ensured that a critical assessment was undertaken of all the relevant epidemiological, behavioural, and environmental information. The gathering, organising, and prioritising of the information was facilitated by the process.

Conclusions-The use of a model such as PRECEDE-PROCEED can enhance the development of a child injury prevention program. In particular, the process can facilitate the identification of appropriate objectives which in turn facilitates the development of suitable interventions and evaluation methods.

(Injury Prevention 1997; 3: 282-287)

Keywords: child pedestrian injury; health promotion planning; models

Injury prevention is recognised as a major public health priority in Australia and other countries. ${ }^{12}$ Pedestrian injury is a leading cause of injury death for Western Australian children with 3.2/100 000 fatalities per year. ${ }^{1-4}$ For $\vec{\sigma}$ those who survive being hit by a vehicle, theinjuries are usually severe. About $80 \%$ of $\omega$ critically injured child pedestrians have severe head injuries. ${ }^{5}$ Children aged 5-9 years who suffer a pedestrian injury spend an average of 30 days in hospital and the direct costs are substantial. ${ }^{67}$

Pedestrian safety is a complex problem that $\stackrel{\oplus}{\varnothing}$ requires multiple interventions at national, $\stackrel{\mathscr{}}{3}$ state, and local levels. A multifaceted local level approach can involve a combination of: pedestrian skills training, parent education, $\varnothing$ teacher education, legislation, environmental modifications, and vehicle design changes. This combined approach is more likely to yield effective outcomes than any single strategy. ${ }^{8-11}$ 응

Program planning is an aspect of injury

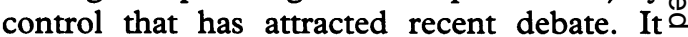
seems that inadequate planning has been one $\overrightarrow{\overrightarrow{0}}$ of the major reasons for ineffective injury 3 control and other health promotion interventions in the past. ${ }^{12}$ Increasing attention has been given, therefore, to the use of recognised planning models to enhance the quality of injury control interventions. A significant proportion of programs, however, are devel- $\stackrel{D}{\leftarrow}$ oped with relatively little consideration given to planning frameworks or theoretical 의 models. $^{81314}$

One of the benefits of using planning models and relevant theories is the likelihood of $\mathcal{O}$ improved rigour in identifying factors on which $₹$

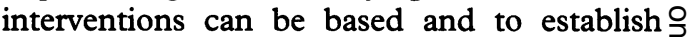
more appropriate objectives. This, in turn, $>$ influences better quality evaluation designs for programs. Planning models can also provide a N holistic picture of a health promotion program and thereby ensure that key components are appropriately and adequately addressed and $\omega$ evaluated..$^{14-16}$

The purpose of this paper is to demonstrate how the PRECEDE-PROCEED model ${ }^{17}$ was adapted and applied as a framework for planning the Child Pedestrian Injury Prevention Project (CPIPP).

CPIPP has been planned as a three year $\frac{}{1}$ intervention trial to assess the effect of a comprehensive program aimed at reducing pedestrian injuries in schoolchildren aged $5-\frac{\delta}{0}$ 9 years. The program includes variable applications of school based student, parent, tea- $\frac{\bar{\partial}}{2}$ cher, and community education, as well as? environmental interventions. The interventions are based on relevant components of 
behavioural learning theories and involve aspects of community development to ensure the active involvement of the schools and their communities. ${ }^{13} 1416-18$

Two communities in the Perth metropolitan area are receiving CPIPP interventions. One community is receiving the school based program only and the other, the school based program plus community and environmental interventions. A third community is being used as a comparison group. In total, 47 schools, 2440 children, 103 teachers, and 2440 parents are involved in the project. Extensive process, impact, and outcome evaluation procedures are being utilised.

\section{A framework for planning an injury prevention program}

With increasing experience in developing injury prevention programs there has also been an improvement in the sophistication of the planning process. As program planners improve their planning skills more of the better planned programs are likely to be based on sound theory. Haddon's injury countermeasures, for example, have been widely used and there has been some recent application of the PRECEDE-PROCEED model. ${ }^{8}$

The PRECEDE model, and its more recent updated version known as PRECEDE-PROCEED, have been referred to in over 500 publications, and used as the basis of planning numerous other health and injury prevention programs. ${ }^{1719} \mathrm{~A}$ value of the model is that it forces the planner to assess thoroughly the factors associated with the problem that is the focus of concern. A series of diagnoses precedes the development of the interventions, their implementation, and evaluation.
Through our experience in conducting training workshops on health promotion planning during the last decade we have found that minor modifications enhance acceptance of the PRECEDE-PROCEED model by health promotion practitioners. Two main changes in particular have facilitated its use. First, the model has been reversed in format, with phase one commencing on the left rather than on the right of the diagram. Second, some changes have been made to the name of each phase. The following are the name changes with the original titles in parentheses: (1) Social factors assessment (social diagnosis); (2) epidemiological factors assessment (epidemiological diagnosis); (3) behavioural and environmental factors assessment (behavioural and environmental diagnosis); (4) contributing factors assessment (educational and administrative diagnosis); (5) intervention strategy selection; and (6) evaluation (refer to figure). ${ }^{17}$

The starting point for planning the CPIPP was phase 2, the epidemiological factors assessment. Once it was firmly established that pedestrian injury involving 5-9 year old children was a significant priority problem in Western Australia, the planning team considered phase 1, the social factors assessment, in its selection of one comparison and two study communities.

\section{STEP 1-THE EPIDEMIOLOGICAL FACTOR} ASSESSMENT

This step involved identifying the epidemiological details of the problem and characteristics of the groups at risk. The information reviewed included mortality and morbidity data as well as risk factors identified in a previous analytical epidemiological study that assessed factors

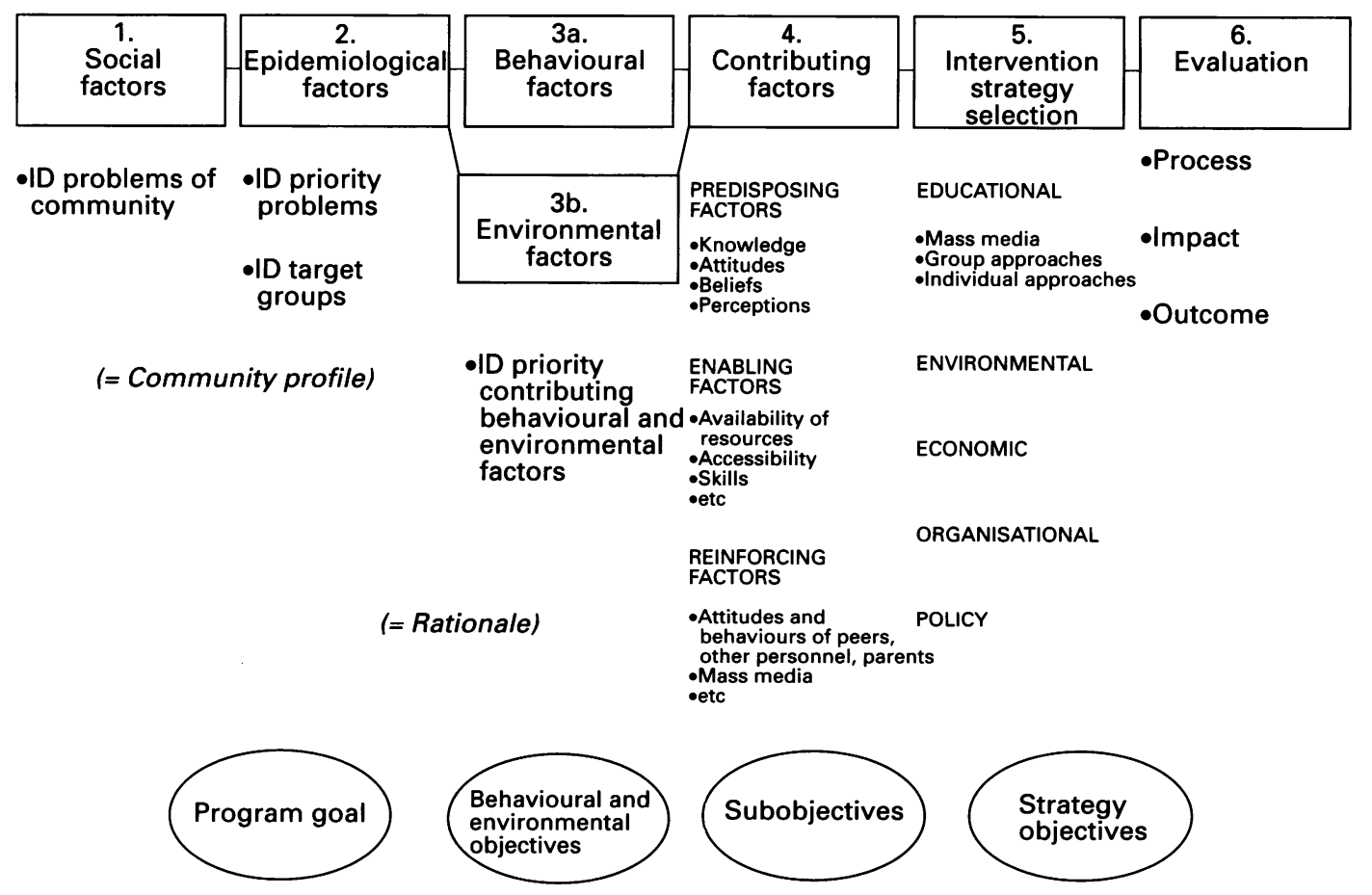

Figure 1 Health promotion planning framework. Adapted from L Green and M Kreuter, 1991 (PRECEDE-PROCEED framework $)^{17}$ and $P$ Hawe, $D$ Degeling, and $\mathcal{F}$ Hall, $1990 .{ }^{1}$ 
contributing to childhood pedestrian injury in Western Australia. ${ }^{20}$ This was supported by data from health department records and other relevant literature. ${ }^{2}$ Some of the key information identifying child morbidity and mortality due to traffic related trauma as a priority problem included:

- Pedestrian injury was the main cause of injury death for Western Australian children

- The rate of child pedestrian injury deaths per year in Western Australia was 3.2/ 100000 , which was higher than the mean Australian rates

- The injuries sustained by child pedestrians hit by a vehicle are usually severe

- $80 \%$ of critically injured child pedestrians have severe head injuries

- The average hospitalisation of 5-9 year old pedestrian injury victims is 30 days

- The direct cost per child pedestrian injury victim is estimated at $\mathrm{A} \$ 100000^{67}$

It was also found that parents and teachers of young children perceived pedestrian injury to be a significant health problem.

This information was used to help define the target groups for the CPIPP. These two groups were: primary target groups-5-9 year old children, their teachers, and parents and secondary target groups-school administrators, city officials, legislators, police, road safety advisory committee, and other residents. Based on this information a program goal was established: a reduction in 5-9 year old child pedestrian injuries in community $\mathrm{A}$ within three years. While it is usually preferable to set a specific rate of change, it was not possible in this case. Injury reporting systems are still insufficiently developed in Western Australia to allow meaningful comparison of injury mortality and morbidity data between the three surburban communities selected for the CPIPP.

\section{STEP 2-THE BEHAVIOURAL AND} ENVIRONMENTAL ASSESSMENT

In this phase of the planning process, factors causally associated with child pedestrian injuries were identified. First, behavioural and second, environmental factors were considered as risk factors, and behavioural and environmental objectives were developed for each risk factor. It is standard practice to state the amount of change expected for each of the risk factors. However, this is usually not possible until substantial baseline data have been collected on the target groups and the relevant environments in which they perform the at-risk behaviours. The planning of all programs should entail the compilation of some data. However, many programs are not well enough funded to conduct adequate data collection to allow all the objectives to be stated with precise, expected rates of change. This limitation was experienced to some extent for the CPIPP even though extensive data were collected at baseline. The amount of change expected by the intervention was incorporated into the objectives discussed below, wherever the baseline data were sufficient for an estimation to be made.

As well as the baseline data, reference was made to the relevant literature and officiat health statistics to identify factors causally? related to child pedestrian injuries. The relative importance and changeability of each factof was assessed based on procedures recom동 mended by Green and Kreuter. ${ }^{17}$

For the behavioural assessment, the main risk factors and behavioural objectives were identi fied for the two primary target groups, child pedestrians aged 5-9 years, and their parent $\vec{P}$ or guardians. Two main risk factors were identified: inappropriate road crossing beha. viours, and children not seeking help to cros\$ the roads. Five behavioural objectives were formulated to guide interventions aimed at reducing the effect of the risk factors.

Three risk factors were seen to be mosf relevant as parental influences on the roadcrossing behaviours of the children. These included: parents failing to supervise the children at road crossing; parents not teaching their children appropriate road crossing proce $\frac{\Phi}{7}$ dures; and parents not modelling appropriate road crossing behaviours. One behaviourab objective was developed for each of these risk factors.

For the environmental assessment, a total of five main risk factors and eight environmenta objectives were identified for the three generap groups of relevant environmental factors traffic volume and speed, road design, and roadside obstacles.

STEP 3-CONTRIBUTING FACTORS ASSESSMEN Multiple factors contribute to each of the behavioural and environmental risk factors identified in the preceding step. These con tributing factors are classified into predispos ing, enabling, and reinforcing factors. The predisposing factors are antecedents to beha $\frac{0}{3}$ viour that provide motivation for actions. The include knowledge, attitudes, beliefs, and perceived needs and abilities, including self̂f efficacy. Enabling factors are regarded as conditions of the environment that facilitat the performance of action by individuals of organisations. They make it possible fon motivation to be realised; that is they enable people to act on their predispositions. Included are availability, accessibility and affordability of resources, supportive policies, as well as new skills that are needed for behavioural of environmental changes. The reinforcing fac? tors provide rewards or incentives for theo continuation of behaviours. Social supporto peer influences, and influences from other significant people such as health professionals $\underset{\Omega}{\mathbb{D}}$ parents and teachers, are all reinforcing factors? They also include social benefits, physicab benefits, tangible or imagined rewards, anc mass media promotions. The various predis posing, enabling, and reinforcing factors may? be either barriers or facilitators to action. ${ }^{14} 17$

The PRECEDE-PROCEED model recommends identifying these factors for each 
behavioural and environmental risk factor. This is a relatively straightforward process when only a few risk factors are identified as priorities for action. However, today most health problems are multicausal and therefore require multiple interventions.

A total of 10 behavioural and environmental risk factors were identified to explain the majority of pedestrian injuries. The main contributing factors for the two primary target groups and for each of the three main groups of environmental factors, are listed below. Subobjectives were identified for each contributing factor. ${ }^{15}$

In total, 20 predisposing, enabling, and reinforcing factors were found to effect the behavioural and environmental risk factors and some contributing factors are common to more than one risk factor. Predisposing factors related directly to child pedestrians included: lack of knowledge about safe road crossing behaviour, and perception of low risk of injury while crossing busy roads. The enabling factors for this group included: inability to identify safer road crossing sites; poorly developed road crossing skills; lack of social skills required to ask people to help them cross roads; and inadequate school road safety education. Two reinforcing factors were: parents allowing children to cross roads alone, and parents' perceptions that their children have adequate abilities to cross roads safely, unaccompanied.

STEP 4-INTERVENTION STRATEGY SELECTION By this stage of the planning sequence, the main factors that seem to be associated with the injury problem, in this case the injuries to child pedestrians, have been identified. The relevant factors have become more specific with each step in the sequence, that is the two

The CPIPP interventions

\begin{tabular}{|c|c|c|}
\hline Strategies & Channel of communication & Purpose \\
\hline $\begin{array}{l}\text { School based } \\
\text { Students }\end{array}$ & $\begin{array}{l}\text { Nine pedestrian safety classroom } \\
\text { lessons per year for three years. } \\
\text { Booster sessions during the year }\end{array}$ & $\begin{array}{l}\text { To provide students with safety } \\
\text { related: } \\
\text { Knowledge } \\
\text { Affective education } \\
\text { Social skills development } \\
\text { Decision making } \\
\text { Assertive communication } \\
\text { Opportunities to practice road } \\
\text { crossing behaviour }\end{array}$ \\
\hline Parents & Nine home activities per year & $\begin{array}{l}\text { To actively involve parents in the } \\
\text { pedestrian safety education of their } \\
\text { children and reinforce messages } \\
\text { learnt at school }\end{array}$ \\
\hline Teachers & $\begin{array}{l}\text { Pedestrian safety teaching resource. } \\
\text { Half day teacher training. Follow } \\
\text { up support }\end{array}$ & $\begin{array}{l}\text { To familiarise teachers with the } \\
\text { pedestrian safety education re- } \\
\text { source 'Crossing Roads' and } \\
\text { provide support for its } \\
\text { implementation }\end{array}$ \\
\hline $\begin{array}{l}\text { Community based } \\
\text { Media }\end{array}$ & $\begin{array}{l}\text { Community newspapers and other } \\
\text { local media }\end{array}$ & $\begin{array}{l}\text { To raise community awareness of } \\
\text { pedestrian safety }\end{array}$ \\
\hline $\begin{array}{l}\text { Community } \\
\text { advisory group }\end{array}$ & $\begin{array}{l}\text { Monthly meetings of relevant } \\
\text { community opinion leaders }\end{array}$ & $\begin{array}{l}\text { To increase community } \\
\text { Awareness of pedestrian safety: } \\
\text { To identify and recommend } \\
\text { environmental and policy changes } \\
\text { concerning pedestrian safety }\end{array}$ \\
\hline $\begin{array}{l}\text { Safe routes to } \\
\text { school project }\end{array}$ & $\begin{array}{l}\text { Monthly meetings of community } \\
\text { advisory committee. Newsletters } \\
\text { to parents of all primary } \\
\text { schoolchildren }\end{array}$ & $\begin{array}{l}\text { To identify safer routes for children } \\
\text { to travel to school }\end{array}$ \\
\hline
\end{tabular}

behavioural and the five environmental factors were quite broad. They were then further refined as specific predisposing, enabling, and reinforcing factors. Similarly, a broad program goal was identified in the epidemiological factors assessment, followed by more specific behavioural and environmental objectives, which were examined further by subobjectives. During step 4, strategy objectives were developed to address each of the subobjectives.

Thirteen main strategy objectives were developed to enable the subobjectives to be met. Some of the strategy objectives relate to more than one of the subobjectives. 'Create a quality school based pedestrian safety education program' is an example of this.

The intervention strategies were then selected to address these strategy objectives. Successful attainment of these strategy objectives should lead to a change in the subobjectives (phase 4), behavioural and environmental objectives (phase 3), and ultimately in a change in the program goal (phase 2). The CPIPP aims to test whether there were significant changes in all of the objectives due to the three year intervention program.

To maximise the likely impact of the intervention strategies, it was recognised that a combination of educational and environmental approaches were needed. The educational strategies referred to here can be classified into two main types. First, there are those activities that aim to directly influence road crossing behaviour. This education is being delivered by mass media, group approaches, and individual approaches. The main target groups here are children, their parents or guardians, as well as their teachers. In-service training of teachers to effectively conduct road safety education for the students in schools is an example of this education.

The second type of education involves support for the children's road crossing behaviours by influencing environmental changes that help make the roads safer. Individual communication with appropriate opinion leaders in the study community, including city councillors and staff, and members of the Road Safety Advisory Committee, are examples. It also includes the provision of mass media information directed to residents to increase their awareness about the need for environmental changes, such as lowering speed limits and the installation of roundabouts, and to increase their support for such changes.

The table summarises the intervention strategies that were developed based on the strategy objectives. Specific details of these strategies are presented elsewhere (D Cross et al; paper presented at the Third International Conference on Injury Prevention and Control, Melbourne, 18-22 February 1996).

\section{Discussion}

The use of PROCEED-PRECEDE as a basis for planning injury prevention interventions can facilitate the process in several ways. Use of the model forces the planner to assess both qualitative and quantitative data to identify 
priorities and to justify why a particular health related problem is selected for intervention. The model considers that health related problems are influenced by multiple, interrelated factors.

Rating the relative importance and changeability of the risk factors assists the selection of the most appropriate areas to be targeted for change. Both behavioural and environmental influences can be identified by this process. The identification and assessment of the predisposing, enabling, and reinforcing factors for each of the main risk factors, helps to show their relative importance as contributing factors.

The orderly and sequential nature of the model facilitates the selection of program goals, behavioural and environmental objectives, and the subobjectives on which a program can be based. This, in turn, ensures that consideration is given to many of the relevant factors as a basis for selecting appropriate intervention strategies. That is, appropriate diagnoses are made before the intervention is designed. During the process, target groups can be identified more precisely and their needs can be assessed more accurately. Prompting the writing of clear, measurable goals and objectives, is another strength of the model. This directs the development of process, impact, and outcome evaluation of the program.

In summary, the PRECEDE-PROCEED model provides a useful checklist addressing many of the main components that need to be considered during program planning. This checklist function can be presented as a summary diagram (for example the figure) which helps to clarify the potentially complex process of planning. The ultimate benefit of the model is that appropriate interventions are likely to result and the likelihood of a rigorous evaluation design is enhanced.

As well as facilitating the planning of the program, the model can assist the process of monitoring progress in achieving the objectives. In the case of CPIPP, a much more detailed version of the figure was constructed that included all the relevant factors and objectives identified within the epidemiological, behavioural and environmental, and contributing factor assessments, as well as the strategy objectives. This figure was produced as a flowchart, with lines linking the appropriate factors and objectives in each phase. Several months after the commencement of the CPIPP interventions, a review was undertaken to assess the implementation of the program. As part of this assessment, the detailed flowchart was consulted. The strategy objectives and subobjectives were reviewed to ensure our process evaluation procedures were assessing the extent to which those objectives were being implemented. The strategies associated with the behavioural objectives were found to be implemented adequately. However, there were significant deficiencies in the implementation of the environmental oriented strategies. The program management committee were consequently made aware of the need to direct more resources to this aspect of the project.

\section{LIMITATIONS}

There are many approaches to planning health promotion and injury prevention programs No one approach is without its limitations and this is equally true for PRECEDE-PROCEEDE In the case of child pedestrian injury preven $\overline{\bar{A}}$ tion, the planning process is complex becaus of the interaction of many variables and the different target groups that need to be the recipients of the interventions. The relativel.9 complex nature of both pedestrian injurz causation and the behavioural and environe mental interventions to reduce the problemp makes utilisation of the framework an involveq process. The users will therefore incur somie opportunity costs because the level of effort is substantial. The benefits, though, are that much more thoroughly planned project can result.

\section{Conclusions}

Despite the onerous task involved in using the PRECEDE-PROCEED model as part of the planning of the CPIPP, the process strengthened the quality of the project. It forced the planners to look critically at the scope of childhood pedestrian injuries, to ascertain thai they were sufficiently important to warrant developing an intervention program. The problem was found to be both important and changeable, and was deemed to be a significant priority for health promotion in Wester Australia.

In conclusion, we believe that the use planning models such as PRECEDE-PROS CEED can play a part in enhancing the qualit of the planning of injury prevention programsD Program planners are encouraged to develog familiarity with such models and theories. The modification and selected application of thes models and theories, or components of them, should further improve the effectiveness of injury prevention programs.

The authors acknowledge colleagues, Curtin University students, teachers, principals, school students, the Project Ad visory Committee, and Community Road Safety Advisory Committee members for their valued contributions to the Committee members for their valued contributions to the
planning of the CPIPP and to the contents of this paper. Than
is also conveyed to Dr Jim Frankish and Dr Bob Cadman, the Institute for Health Promotion Research, University of Britist Colombia; Associate Professor Ken Resnicow and Professor Marshall Kreuter, the School of Public Health, Emo' University for their helpful comments on the manuscript. Th ate Debra Blaze-Temple contributed to some of the initis deas for this paper. We are indebted to the following organisations for funding the project: the Western Australian Health Promotion Foundation (Healthway); The Westero ealth Promotion Foundation (Healthway); The Westero Australia.

1 Department of Human Services and Health. National goats targets and strategies for injury prevention and contrat Canberra: DHHS, 1994

2 Sleet DA, Albany P, Lee N, Stevens M. Injury in Wester Australia. Perth: Health Department of Western Austra lia, 1991 .

3 Australian Bureau of Statistics. Road traffic accidents invot ving casualties (admitted to hospital): Australia. Canberra: ABS, 1987.

4 Roberts I, Norton R. Sensory deficit and the risk of pedestrian injury. Injury Prevention 1996; 1: 12-4. 
5 Harris BH, Schwaitzberg SD, Seman TM, Herrman C. The hidden morbidity of pediatric trauma. 7 Pediatr Surg 1989; 24: $103-6$.

6 Andreassen DC. Preliminary costs for accident types: accident costs for project planning and evaluation. Melbourne: Australian Road Research Board, 1992. (Report No ARR 217.)

7 Andreassen DC. Vehicle repair costs: accident costs for project planning and evaluation. Melbourne: Australian Road Research Board, 1992. (Report No ARR 218.)

8 Gielen A. Health education and injury control: integrating approaches. Health Educ $Q$ 1992; 19: 203-18.

9 Roberts I, Norton R, Dunn R, Hassall I, Lee-Joe $T$. Environmental factors and child pedestrian injuries. Aust f Public Health 1994; 18: 43-6.

10 Roberts I, Ashton T, Dunn R, Lee-Joe T. Preventing child pedestrian injury: pedestrian education or traffic calming. Aust f Public Health 1994; 18: 209-12.

11 Howat P, Binns C, Blaze-Temple D, Corti B. Prevention of alcohol related problems: an overview of health promoalcohol related problems: an overview of health promo1: $87-99$.

12 Kok G. Why are so many health promotion programs ineffective? Health Promotion fournal of Australia 1993; 3: $12-7$
13 Simons-Morton B, Brink S, Simons-Morton D, et al. An ecological approach to the prevention of injuries due to drinking and driving. Health Educ $O$ 1989; 16: 397-411.

drinking and driving. Health Educ $Q$ 1989; 16: $397-411$.
14 Glanz K, Rimer B. Theory at a glance: a guide for health promotion practice. Washington DC: USDHHS, 1995.
,

15 Hawe P, Degeling D, Hall J. Evaluating health promotion: $a$ guide for health workers. Sydney: MacLennan and Petty, 1990.

16 Bjaras $\mathrm{G}$. The potential of community diagnosis as a tool in planning an intervention program aimed at preventing injuries. Accid Anal Prev 1993; 25: 3-10.

17 Green L, Kreuter M. Health promotion planning: an educational and environmental approach. Mountain View: Mayfield, 1991

18 Tones K. Mobilising communities: coalitions and the prevention of heart disease. Health Educ $\mathcal{F}$ 1994; 53: $462-73$.

19 Institute of Health Promotion Research, University of British Columbia. Second Annual Summer Institute on Health Promotion Planning and Evaluation, June 12-16. Vancouver, IBHR, 1995 (course manual).

20 Stevenson M, Jamrozik K, Spittle J. A case control study of traffic risk factors and child pedestrian injuries. Int $\mathcal{f}$ Epidemiol 1995; 24: 1 -8

Editorial Board Member: brief biography JOCELYN PEDDER

Jocelyn Pedder is the President of RONA Kinetics and Associates Ltd, an independent safety research group in Vancouver, Canada. Born in New Zealand, her interest in injury prevention research was initiated as

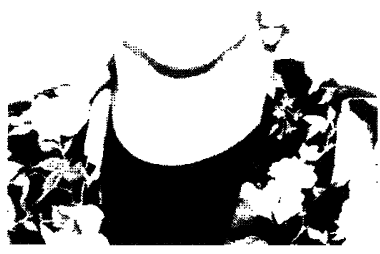
a researcher at the School of Medicine at the University of Auckland when she conducted a study of single vehicle crashes. In 1975 she moved to England to work at the Accident Research Unit of the University of Birmingham. For the next eight years she was involved in the study of real crashes and resulting injuries. Some of this work formed the basis of her doctorate dissertation on the characteristics of motorcycle crashes and the potential for injury prevention.

In 1983 Dr Pedder moved to Canada to join Biokinetics and Associates Ltd, a bioengineering consulting firm in Ottawa. Her work at Biokinetics included the design and development of personal protective equipment and safety specifications. She moved to Vancouver in 1992 to establish RONA Kinetics where her work in the field of safety research continues. Dr Pedder has many published research papers in the field of road trauma and safety, notably on kinematics and injury control in motor vehicle crashes as well as impacts involving pedestrians and bicyclists.

Dr Pedder is actively involved in efforts to advance the state of knowledge on the biomechanics of injury and injury prevention through studies of real crashes. She participates in a number of related national and international technical committees and is a member of the Society of Automotive Engineers. She is currently on the board of directors of the Association for the Advancement of Automotive Medicine. Dr Pedder is also involved in local efforts to reduce road trauma and the incidence of motor vehicle crashes through the implementation of existing research findings and appropriate legislation. 